\title{
Assessment of sheep blastocyst effects on neutral lipids in the uterine caruncular epithelium
}

\author{
D. P. Boshier, R. J. Fairclough*† and H. Holloway \\ Department of Anatomy, University of Auckland, Private Bag, Auckland, and \\ * Ruakura Animal Research Station, Hamilton, New Zealand
}

\begin{abstract}
Summary. Neutral lipids in the maternal uterine caruncular epithelium were studied by histochemical localization with Oil Red O. Results using a scoring system of 1 (negligible lipid) to 5 (maximal lipid) showed that intraepithelial lipid stores were minimal until Days 7-8 of the oestrous cycle and then increased to have a mean score of 4.4 on Days 14-15. In early pregnancy, although relatively high with a mean score of $3 \cdot 2$ at Day 15-16, such neutral lipids were significantly lower than those present at a comparable stage in the oestrous cycle. Thereafter, levels declined to a mean score of 1 on Days 21-23 of pregnancy. Such neutral lipid loss appears to be one of the first signs of the maternal response to the implanting embryo and precedes morphological evidence of transformation of either maternal or fetal tissues.
\end{abstract}

\section{Introduction}

The periodic appearance and disappearance of histochemically demonstrable lipids in the uterine epithelium of rats, sheep and cattle during the oestrous cycle is well known (Alden, 1947; Marinov \& Lovell, 1968; Brinsfield \& Hawk, 1973; Boshier \& Holloway, 1973). However, there are relatively few studies of lipid levels in the endometrium in early pregnancy when the blastocyst is in close association with the uterine epithelium and the tissue re-organizations associated with the placental development are not yet evident or have just begun.

Bloch (1939) demonstrated that intra-epithelial osmiophilic granular secretions diminished or vanished when in close proximity with the implanted embryo in albino mice. Alden (1947) observed that osmiophilic lipid was slightly altered in its distribution at the implantation site in albino rats, but could deduce little about lipid levels during pregnancy. Boshier (1976) showed that, by the morning of Day 6 of pregnancy, all traces of intra-epithelial neutral lipids had disappeared from the rat implantation chamber as the result of enhanced esterase activity.

It is of interest to know whether such changes in intra-epithelial neutral lipids are found in other mammalian groups during implantation. This study was therefore undertaken to investigate changes in the patterns of neutral lipid distribution in the sheep uterine epithelium during the oestrous cycle and early pregnancy. Particular attention was given to studying lipid levels in the caruncular epithelium, as it is the site of blastocyst attachment and placental formation (Boshier, 1969).

\section{Materials and Methods}

\begin{abstract}
All tissues examined were obtained from mature mixed-age New Zealand Romney ewes which were pasture-fed and run in the breeding season with teaser or entire rams fitted with brisket-mounted marking crayons. The day on which each ewe was marked during mating is Day 1 of the oestrous cycle. Ewes were studied at Days 3-4 ( $\mathrm{N}=3$ ), 7-8
\end{abstract}

†Present address: Werribee Animal Research Station, Werribee, Melbourne, Victoria 3030, Australia. 

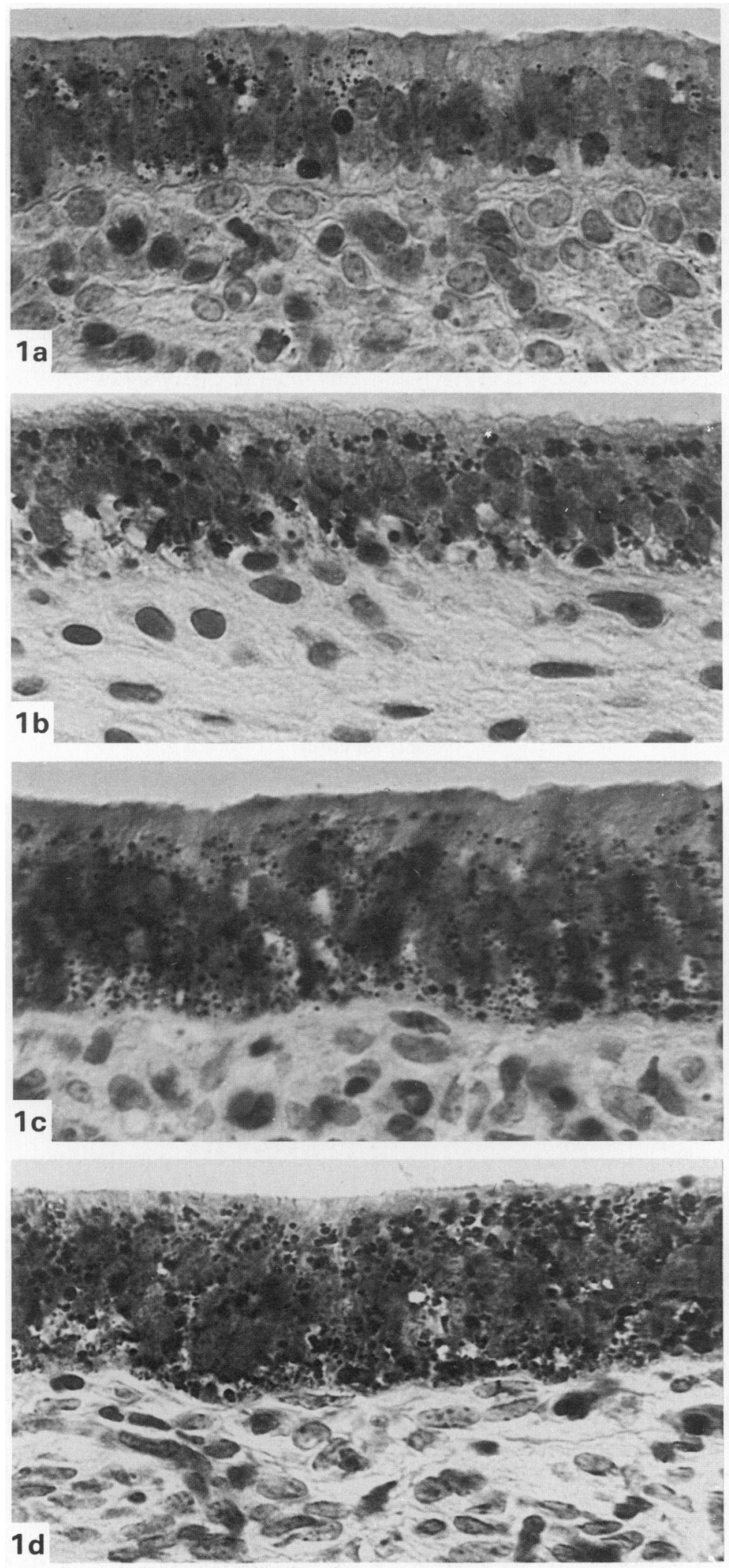
$(\mathrm{N}=4), 10-11(\mathrm{~N}=2)$ and $14-15(\mathrm{~N}=3)$ of the oestrous cycle. Additional ewes were studied at Days 15-16 $(\mathrm{N}=6), 18-19(\mathrm{~N}=3)$ and $21-23(\mathrm{~N}=5)$ after a fertile mating. At the time of slaughter, the uteri of the mated ewes were flushed with saline for embryo collection to confirm pregnancy status. Blocks of uterine caruncular tissue were taken from freshly killed animals and fixed in Baker's formal calcium solution. The tissue blocks were soaked for $24-48 \mathrm{~h}$ in $25 \%$ aqueous sucrose at $4^{\circ} \mathrm{C}$ then frozen on the quick-freeze stage and sectioned at $6 \mu \mathrm{m}$ in a microtome-cryostat $\left(-25^{\circ} \mathrm{C}\right)$.

Three randomly selected blocks of tissue from each animal were sectioned to give in excess of 10 specimens per block which were then stained for liquid hydrophobic neutral lipids with Oil Red $\mathbf{O}$ (Bayliss High, 1977) and counterstained with Mayer's haemalum. Ten sections from each block (donor ewe unknown) to give at least 30 sections per ewe were then randomly selected, examined, and scored $1-5$, as judged by the following criteria: 1 , little/no significant Oil Red O (ORO +) staining seen in the caruncular epithelial cells; 2, sparse ORO + droplets in most cells (Fig. la); 3, some apical and few basal ORO + droplets in all cells (Fig. 1b); 4, ORO + droplets present apically and basally, some lateral to nuclei (Fig. Ic); 5, ORO + droplets larger, numerous, and spread throughout the cytoplasm (Fig. Id).

Statistical analysis of the data was based, after expert advice, on single classification analysis of variance followed by Snedecor's (1956) modification of Tukey's test for comparisons among means.

\section{Results}

As shown in Fig. 2, intra-epithelial neutral lipids were rarely demonstrable during the oestrous cycle until the 7 th or 8 th day, from which time their levels increased, reaching the maximum score of $4.4 \pm 0.05$ (mean \pm s.e.m.) by the 14 th and 15 th days. Significant $(P<0.01)$ differences were shown between the mean scores of the 4 oestrous cycle groups.

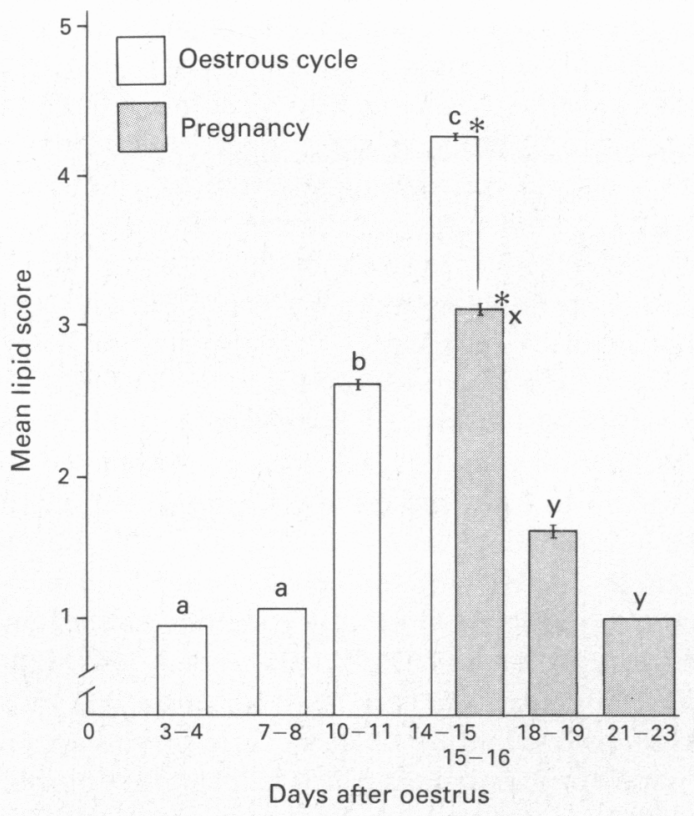

Fig. 2. Intra-epithelial lipid scores during the oestrous cycle and early pregnancy in ewes. In statistical comparisons made using Tukey's test, day groups having the same alphabetic superscripts do not differ at $P=0.05$. ${ }^{*}$ Scores differ at $P<0.05$.

Fig. 1. Representative sections of ovine caruncular epithelium, stained with Oil Red $\mathrm{O}$, which demonstrate the basis of the scoring system used: (a) score $=2$; (b) score $=3$; (c) score $=4$; (d) score $=5$. When necessary, intermediate scores using gradations of 0.5 were allocated. $\times 650$. 
During pregnancy, neutral lipid levels were still high (score $3 \cdot 2 \pm 0 \cdot 12$ ) 15-16 days after mating but decreased markedly during the next 8 days, scoring $1 \cdot 8 \pm 0 \cdot 11$ on Days $18-19$ and reaching negligible levels by the 21 st day of pregnancy. These decreases were of statistical significance $(P<0.01)$ between the 3 day groups. Neutral lipid scores on Day 15-16 of pregnancy were significantly lower than those found on Days $14-15$ of the oestrous cycle $(P<0.05)$.

\section{Discussion}

While appreciating that the use of an ordinal scale for scoring the amount of lipid present in the uterine epithelia studied does involve subjective assessment, albeit within defined constraints, tissue scores are obtained relatively quickly and easily, and if sufficient assessments are made valid conclusions may be drawn from them.

Our demonstration that, during the oestrous cycle of the sheep, stored liquid hydrophobic neutral lipids are not demonstrable histochemically in the uterine caruncular epithelium until about Day 8; thereafter increasing to a maximum by the 14 th or 15 th day, confirms the findings of Brinsfield $\&$ Hawk (1973), although they did not distinguish between caruncular and intercaruncular epithelia. This cyclic increase and decrease in epithelial lipid storage has been shown to depend on prior plasma concentrations of progesterone and oestrogen in the laboratory rat and the sheep. Progesterone facilitates lipid storage and oestrogen increases neutral lipid loss via enhanced esterase activity (Boshier \& Holloway, 1973; Brinsfield \& Hawk, 1973; Boshier \& Katz, 1975).

In early pregnancy in sheep, uterine intra-epithelial neutral lipids decline, despite the fact that plasma progesterone concentrations, normally supporting lipid storage, show no marked change in concentration and values remain similar to those in non-pregnant ewes at mid-cycle (Bassett $e t$ al., 1969). Plasma oestradiol-17 $\beta$ concentrations are also little changed in early pregnancy (Tsang, 1978). These hormone profiles contrast markedly with those in non-pregnant ewes, in which there is a dramatic decline in plasma progesterone values at luteolysis (Bassett et al., 1969) and a sharp increase in the preovulatory plasma oestrogen concentrations (Baird et al., 1976). These results suggest that ovarian hormones do not control the metabolism of lipids during early pregnancy as they do during comparable periods of the oestrous cycle.

The loss of neutral lipids at the implantation site in sheep when a blastocyst is present is similar to that in rats in which the presence of the blastocyst is also necessary since agar droplets comparable in size with the blastocysts do not give the same response (Boshier, 1976). By the 14th day of gestation in the ewe, the blastocyst has expanded sufficiently to fill the uterine horn (Rowson \& Moor, 1966), and soon after shows the first evidence of attachment to the uterine epithelium (Boshier, 1969). As shown by the present results, the pregnant uterine horn containing the expanded blastocyst had a lower lipid score $(P<0.05)$ than a non-pregnant horn of the same age after oestrus. The stimulus to altered intra-epithelial neutral lipid metabolism therefore is the physical presence of trophoblastic tissue close to the uterine epithelium, a characteristic of the attachment phase of embryo implantation (Bloch, 1939; Alden, 1947; Ljungkvist \& Nilsson, 1971; Boshier, 1976). The stimulus must also have been received before Day 15, because the cytochemical evidence of lipid loss reflecting altered intracellular metabolism was apparent by this time.

Suggestions as to the nature of the stimulus which induces these biochemical changes can as yet only be conjectural. The trophoblast may produce oestrogens which diffuse into the uterine epithelium and increase eithelial esterase activity (Boshier, 1976); or possibly the stimulus is the low molecular weight protein released by the trophoblast after Day 13 (Godkin et al., 1982; Heyman et al., 1984). Certainly by Day 21 the tissue transformations involved in the implantation response and placental formation have begun (Boshier, 1969, 1976). Catabolism of the neutral lipids could provide substrates for the cellular re-organization characteristic of this period, for the production of prostaglandins important in the implantation process (Kennedy, 1977; Boshier et al., 1981) and for the metabolic use of the blastocyst. 
These results in sheep confirm earlier findings in rodents, suggesting that altered neutral lipid metabolism in the uterine epithelium adjacent to the trophoblast may be one of the first signs of the morphological changes seen during the maternal response in the events of implantation in mammals.

This study was supported by the Medical Research Council of New Zealand. We thank Mr Iain MacDonald for assistance with the photographic work; Miss Tracey Richardson for preparation of the manuscript; and Mr Ross Lasenby of the Ruakura Animal Research Station, Hamilton, NZ, for assistance with animal preparation.

\section{References}

Alden R.H. (1947) Implantation of the rat egg. Anat. Rec. $97,1-19$.

Baird, D.T., Land, R.B., Scaramuzzi, R.J. \& Wheeler, A.G. (1976) Endocrine changes associated with luteal regression in the ewe; the secretion of ovarian oestradiol, progesterone and androstenedione and uterine prostaglandin $\mathrm{F}_{2 a}$ throughout the oestrous cycle. $J$. Endocr. 69, 275-286.

Bassett, J.M., Oxborrow, T.J., Smith, I.D. \& Thorburn, G.D. (1969) The concentration of progesterone in the peripheral plasma of the pregnant ewe. J. Endocr. 45, 449-457.

Bayliss High, O. (1977) Lipids. In Theory and Practice of Histological Techniques, pp. 168-185. Eds J. D. Bancroft \& A. Stevens. Churchill Livingstone, London.

Bloch, S. (1939) Contributions to research on the female sex hormones. The implantation of the mouse egg. $J$. Endocr. 1, 399-411.

Boshier, D.P. (1969) A histological and histochemical examination of implantation and early placentome formation in sheep. J. Reprod. Fert. 19, 51-61.

Boshier, D.P. (1976) Effects of the rat blastocyst on neutral lipids and non-specific esterases in the uterine luminal epithelium at the implantation area. $J$. Reprod. Fert. 46, 245-247.

Boshier, D.P. \& Holloway, H. (1973) Effects of ovarian steroid hormones on histochemically demonstrable lipids in the rat uterine epithelium. $J$. Endocr. 56, 59-67.

Boshier, D.P. \& Katz, J.M. (1975) Effects of ovarian steroid hormones on esterases in the rat endometrium. $J$. Endocr. 64, 465474.

Boshier, D.P., Holloway, H. \& Millener, N.M. (1981) Triacylglycerols in the rat uterine epithelium during the oestrous cycle and early pregnancy. $J$. Reprod. Fert. 62, 441-446.
Brinsfield, T.H. \& Hawk, H.W. (1973) Control by progesterone of the concentration of lipid droplets in epithelial cells of the sheep endometrium. J. Anim. Sci. 36, 919-922.

Godkin, J.D., Bazer, F.W., Moffatt, J., Sessions, F. \& Roberts, R.M. (1982) Purification and properties of a major, low molecular weight protein released by the trophoblast of sheep blastocysts at Day 13-21.J. Reprod. Fert. 65, 141-150.

Heyman, Y., Camous, S., Fevre, J., Meziou, W. \& Martal, J. (1984) Maintenance of the corpus luteum after uterine transfer of trophoblastic vesicles to cyclic cows and ewes. J. Reprod. Fert. 70, 533-540.

Kennedy, T.G. (1977) Evidence for a role of prostaglandins in the initiation of blastocyst implantation in the rat. Biol. Reprod. 16, 286-291.

Ljungkvist, I. \& Nilsson, O. (1971) Ultrastructure of rat uterine luminal epithelium at functional states compatible with implantation. Z. Anat. EntwGesch. 135, 101-107.

Marinov, U. \& Lovell, J.E. (1968) Cytology of the bovine uterine epithelium during the estrous cycle. Am. J. Vet. Res. 29, 13-30.

Rowson, L. \& Moor, R.M. (1966) Development of the sheep conceptus during the first fourteen days. $J$. Anat. 100, 777-785.

Snedecor, G.W. (1956) Statistical Methods, 5th edn, pp. 251-254. Iowa State University Press, Ames.

Tsang, P.W. (1978) Plasma levels of estrone sulfate, free estrogens and progesterone in the pregnant ewe throughout gestation. Theriogenology 10,97-110.

Received 24 July 1986 